Supporting Information

\title{
A Bottom-Up Approach To Preserve Thioamide Residue Stereochemistry during Fmoc Solid-Phase Peptide Synthesis
}

Luis A. Camacho III, Bryan J. Lampkin, Brett VanVeller*

Department of Chemistry, lowa State University, Ames, lowa 50011

Contents

Page

GENERAL INFORMATION

S2

SYNTHETIC PROCEDURES

S3

UPLC Results for Figure 1 of main text:

S5

SPPS PROCEDURES

S7

HPLC TRACES OF PEPTIDES

S8

NMR SPECTRA

S13

ANALYTICAL UPLC TRACES

S18

COMPUTATIONAL DETAILS

S19

REFERENCES

S21 


\section{General Information:}

Materials: Silica gel $(40 \mu \mathrm{m})$ was purchased from Grace Davison. Protected amino acids and Fmoc-Glychlorotrityl resin purchased from Chem-Impex. $\mathrm{P}_{4} \mathrm{~S}_{10}$ purchased from Acros Organics. Anhydrous potassium carbonate and iodomethane purchased from Fisher. Solvents initially purchased from Fisher and THF, DCM, and DMF were dried via solvent system. Hydrogen sulfide, diisopropyl ethylamine (DIEA), and 1,8-Diazabicyclo[5.4.0]undec-7-ene (DBU) were purchased from Sigma-Aldrich. N-methylmorpholine was purchased from Protein Technologies Inc.

\section{Experimental:}

NMR Spectroscopy: ${ }^{1} \mathrm{H}$ and ${ }^{13} \mathrm{C}$ NMR spectra for all compounds were acquired in deuterated solvents (as indicated) on a Bruker Spectrometer at the field strengths reported in the text. The chemical shift data are reported in units of $\delta(\mathrm{ppm})$ relative to residual solvent.

Liquid Chromatography: Peptide analysis was accomplished on a Waters Acquity UPLC System with TUV detection and a BEH C18 column $1.7 \mu \mathrm{m}$. UPLC solvents contained water with $0.1 \%$ formic acid or acetonitrile with $0.1 \%$ formic acid.

For larger peptides and final analysis, Waters HPLC System was used. Detection was acquired 2998 Photodiode Array Detector and a SunFire C18 column $5 \mu \mathrm{m}$. HPLC solvents contained water with $0.1 \%$ TFA and acetonitrile with $0.1 \%$ TFA.

Mass Spectrometry: Masses of compounds were taken initially for LRMS (ESI) via Waters Acquity QDa Detector. HRMS data collected via Agilent QTOF 6540 MSMS with ESI ionization. Chemical formulas found from HRMS data were obtained via Agilent MassHunter software equipped with the HRMS QTOF. Peptides were also analyzed using Axima Confidence MALDI-TOF calibrated via Anaspec Peptide Mass Spec Standard Mixture 1 which includes Des-Arg1-Bradykinin $\left(\left[\mathrm{M}+\mathrm{H}^{+}\right]\right.$905.3 Da), Angiotensin I $\left(\left[\mathrm{M}+\mathrm{H}^{+}\right]\right.$ 1297.3 Da), and Neurotensin $\left(\left[\mathrm{M}+\mathrm{H}^{+}\right]\right.$1674.4 Da). 


\section{SYNTHETIC PROCEDURES}

\section{Synthesis of 4 (Z-Phe $\left.{ }^{(\mathrm{S})}-\mathrm{Ala}-\mathrm{OMe}\right)$.}<smiles>[R]C(=O)OCc1ccccc1</smiles><smiles>[Y20]C(Cc1ccccc1)C(=O)O</smiles>

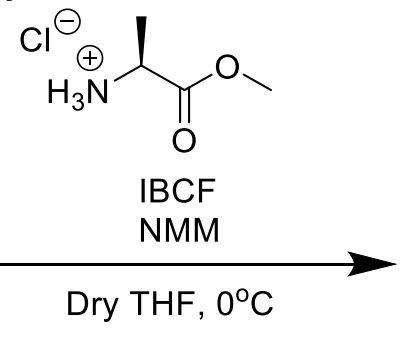<smiles>[Z]N[C@@H](Cc1ccccc1)C(=O)N[C@@H](C)C(=O)OC</smiles>

Based on a previously reported procedure, ${ }^{1}$ Z-L-phenylalanine $(1.17 \mathrm{~g}, 3.9 \mathrm{mmol})$ was dissolved in dry THF and cooled in a dry ice/acetone bath. Isobutyl chloroformate $(0.5 \mathrm{~mL}, 0.5 \mathrm{~g}, 4 \mathrm{mmol})$ was added dropwise followed by dropwise addition of $N$-methyl morpholine (NMM) $(1.4 \mathrm{~mL}, 1.3 \mathrm{~g}, 12 \mathrm{mmol})$ to produce a white precipitate. The mixture was stirred for $5 \mathrm{~min}$. after which solid L-Ala-OMe hydrochloride salt $(0.60 \mathrm{~g}, 4.3 \mathrm{mmol})$ was added in one portion. The mixture was stirred for additional $30 \mathrm{~min}$ and filtered to remove the precipitate. Volatiles were removed in vacuo to yield the Z-Phe-Ala-OMe product and used without further purification. Physical and spectroscopic data were in agreement with literature reports $^{2}$ (See Figure S3, S8)(1.43 g, 95\% Yield) ${ }^{1} \mathrm{H}$ NMR, $\left(400 \mathrm{MHz}, \mathrm{CDCl}_{3}\right) \delta 1.32(3 \mathrm{H}, \mathrm{d}, \mathrm{J}=4 \mathrm{~Hz}) 3.07$ $(2 \mathrm{H}, \mathrm{d}, \mathrm{J}=4 \mathrm{~Hz}) 3.70(3 \mathrm{H} \mathrm{s}) 4.54(2 \mathrm{H}, \mathrm{m}) 5.10(2 \mathrm{H}, \mathrm{dd}, \mathrm{J}=16,12 \mathrm{~Hz}) 5.52(1 \mathrm{H}, \mathrm{d}, 8 \mathrm{~Hz}) 6.57(1 \mathrm{H}, \mathrm{d}, \mathrm{J}=$ $4 \mathrm{~Hz}) 7.35-7.17(10 \mathrm{H} \mathrm{m})$<smiles>[Z]N[C@@H](Cc1ccccc1)C(=O)N[C@@H](C)C(=O)OC</smiles>

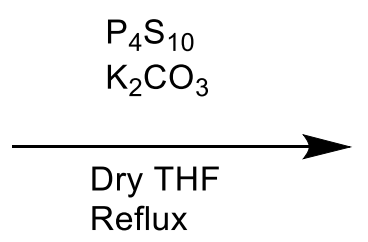<smiles>[Z]N[C@@H](Cc1ccccc1)C(=S)N[C@@H](C)C(=O)OC</smiles>

Based on a previously reported procedure, ${ }^{1}$ Z-Phe-Ala-OMe $(1.34 \mathrm{~g}, 3.50 \mathrm{mmol})$ was dissolved in dry THF. $\mathrm{P}_{4} \mathrm{~S}_{10}(1.56 \mathrm{~g}, 3.51 \mathrm{mmol})$ and potassium carbonate $(1.48 \mathrm{~g}, 10.73 \mathrm{mmol})$ were added in one portion and the mixture was heated to reflux for $4 \mathrm{~h}$. The mixture was filtered, and the filtrate was concentrated in vacuo. The residue was purified via silca-gel chromatography (1:1 ethyl acetate:hexane) to yield the final compound, Z-Phe(S)-Ala-OMe as a yellow oil. (Figure S4, S5, S9). (1.25 g. 89\% Yield). ${ }^{1} \mathrm{H}$ NMR, (400 $\mathrm{MHz}$, Acetone- $\left.d_{6}\right) \delta 1.47(3 \mathrm{H}, \mathrm{d}, \mathrm{J}=8 \mathrm{~Hz}) 3.03,(1 \mathrm{H}, \mathrm{dd}, \mathrm{J}=8,4 \mathrm{~Hz}) 3.29(1 \mathrm{H}, \mathrm{dd}, \mathrm{J}=16,4 \mathrm{~Hz}) 3.69(3 \mathrm{H}, \mathrm{s})$ $4.89(1 \mathrm{H}, \mathrm{ddd} \mathrm{J}=16,8,4 \mathrm{~Hz}) 5.06(3 \mathrm{H}, \mathrm{m}) 6.61(1 \mathrm{H}, \mathrm{d}, \mathrm{J}=8 \mathrm{~Hz}), 7.35-7.20(10 \mathrm{H}, \mathrm{m}) 9.49(1 \mathrm{H}, \mathrm{d}, \mathrm{J}=4 \mathrm{~Hz})$. ${ }^{13} \mathrm{C}$ NMR $(100 \mathrm{MHz}$, acetone-d6) $\delta 204.8,171.4,155.7,137.5,137.2,129.4,128.3,128.2,127.7,127.5$, 126.5, 65.9, 62.3, 53.4, 51.7, 41.4, 18.4, 17.0, 16.0. Calc Mass [M+H+] 401.1530; Obs: 401.1533. Molecular Formula: $\mathrm{C}_{21} \mathrm{H}_{24} \mathrm{~N}_{2} \mathrm{O}_{4} \mathrm{~S}$ 


\section{Synthesis of 5 (Z-Phe(SMe)-Ala-OMe).}<smiles>[Z]N[C@@H](Cc1ccccc1)C(=S)N[C@@H](C)C(=O)OC</smiles>

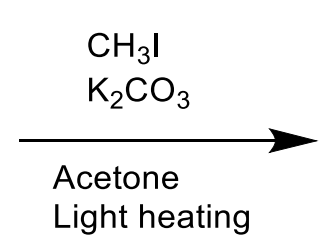<smiles>[Z]N[C@@H](Cc1ccccc1)/C(=N/[C@@H](C)C(=O)OC)SC</smiles>

Z-Phe(S)-Ala-OMe (4) (0.38 g, $0.95 \mathrm{mmol})$ was dissolved in acetone, followed by addition of Mel $(0.27 \mathrm{~g}$, $0.12 \mathrm{~mL}, 1.9 \mathrm{mmol})$ and potassium carbonate $(0.39 \mathrm{~g}, 2.83 \mathrm{mmol})$. The mixture was heated to $35^{\circ} \mathrm{C}$ and monitored via TLC. Upon completion, the mixture was filtered, and the filtrate was concentrated in vacuo. The resulting filtrate was purified via silica-gel chromatography (1:1 ethyl acetate:hexane) to yield the product Z-Phe(SMe)-Ala-OMe as a green oil. (Figure S6, S7, S10). (0.34 g, 88\% yield). ${ }^{1 \mathrm{H}}$ NMR (Mixture of $1: 3$ rotamers) $\left(400 \mathrm{MHz}\right.$, Acetone- $\left.d_{6}\right) \delta=1.12(1 \mathrm{H}, \mathrm{d}, \mathrm{J}=8 \mathrm{~Hz})^{\star} 1.22(3 \mathrm{H} \mathrm{d}, \mathrm{J}=8 \mathrm{~Hz}) 2.22(1 \mathrm{H}, \mathrm{s})^{\star} 2.55(3 \mathrm{H}$ s) $3.00(1 \mathrm{H} \mathrm{dd}, \mathrm{J}=14,8 \mathrm{~Hz}) 3.24(1 \mathrm{H} \mathrm{dd}, \mathrm{J}=14,8 \mathrm{~Hz}) 3.62(3 \mathrm{H} \mathrm{s}) 3.63(1 \mathrm{H}, \mathrm{s})^{*} 4.41(1 \mathrm{H} \mathrm{q}, \mathrm{J}=8 \mathrm{~Hz}) 4.59$ $(0.3 \mathrm{H}, \mathrm{q}, \mathrm{J}=8 \mathrm{~Hz})^{\star} 4.97(1 \mathrm{H} \mathrm{q}, \mathrm{J}=8 \mathrm{~Hz})^{*} 5.11(3 \mathrm{H} \mathrm{m}) 6.42(1 \mathrm{H} \mathrm{d}, \mathrm{J}=8 \mathrm{~Hz}) 6.89(0.5 \mathrm{H}, \mathrm{d}, \mathrm{J}=8 \mathrm{~Hz})^{*} 7.29(13 \mathrm{H}$ m). ${ }^{13} \mathrm{C}$ NMR (100 MHz, acetone-d6) $\delta 173.0,167.0,156.4,138.4,138.1,138.0,130.8,130.4,130.2$, $129.4,129.3,129.3,129.1,129.0,128.7,128.7,127.8,127.5,66.8,60.2,58.9,55.2,54.9,52.2$, 40.4, 39.8, 19.9, 19.3, 17.9, 14.2, 12.7. HRMS [M+H+] calc: 415.1686; Obs: 415.1689; Molecular Formula: $\mathrm{C}_{22} \mathrm{H}_{26} \mathrm{~N}_{2} \mathrm{O}_{4} \mathrm{~S}$

${ }^{*}$ Next to parentheses indicates rotamer peaks found in ${ }^{1} \mathrm{H}$ NMR.

\section{Synthesis of thioacylating agents.}

Synthesis of thioacylating reagents was carried out according to previous procedures with matching spectra. ${ }^{1,3}$ 


\section{UPLC Results for Figure 1 of main text:}

Table S1. UPLC Gradients for dipeptide diastereomer resolution

\begin{tabular}{|r|r|r|r|r|r|}
\hline \multicolumn{3}{|c|}{ Thioamide (4) } & \multicolumn{3}{|c|}{ Thioimidate (5) } \\
\hline $\begin{array}{c}\text { Time } \\
\text { (minutes) }\end{array}$ & \% Water & \% Acetonitrile & $\begin{array}{c}\text { Time } \\
\text { (minutes) }\end{array}$ & $\%$ Water & \% Acetonitrile \\
\hline 0.00 & 50 & 50 & 0.00 & 50 & 50 \\
3.00 & 35 & 65 & 3.00 & 40 & 60 \\
3.01 & 0 & 100 & 3.01 & 0 & 100 \\
3.50 & 0 & 100 & 3.50 & 0 & 100 \\
3.51 & 60 & 40 & 3.51 & 50 & 50 \\
4.00 & 60 & 40 & 4.00 & 50 & 50 \\
\hline
\end{tabular}

Flow rate was constant at $0.450 \mathrm{~mL} / \mathrm{min}$

\begin{tabular}{|l|l|r|}
\hline Compound & Retention Time (minutes) & Epimer Rention Time (minutes) \\
\hline $\mathbf{4}$ & 1.7 & 2.1 \\
\hline $\mathbf{5}$ & 2.1 & 2.7 \\
\hline $\begin{array}{l}1,3,5 \text {-trimethoxybenzene } \\
\text { (internal standard) }\end{array}$ & 0.7 & N/A \\
\hline
\end{tabular}

Equation used to calculate percent epimerization of dimers for UPLC testing.

Percent Epimerization at Time $t$

$$
=\left(1-\frac{\text { Area of Starting Epimer Peak }}{\text { Area of Starting Epimer Peak }+ \text { Area of Growing Epimer Peak }}\right) * 100 \%
$$

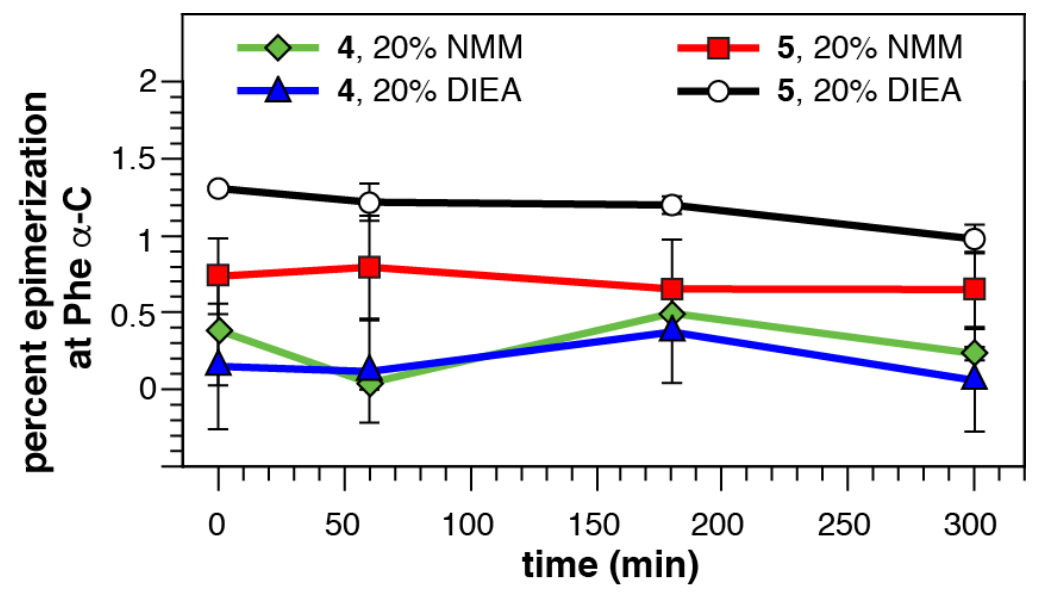

Figure S1. Stability of $\mathbf{4}$ and $\mathbf{5}$ with bases (NMM, DIEA) used commonly during the amino-acid coupling step of SPPS. No appreciable epimerization was observed, which agrees with previous results. ${ }^{3,4}$ 
Table S2. Epimerization Data, average of 3 trials.

Z-F ${ }^{\mathrm{S}} \mathrm{A}-\mathrm{OMe}(4) \quad$ Z-F ${ }^{\mathrm{SMe}} \mathrm{A}-\mathrm{OMe}(5)$

\begin{tabular}{|rcc|rcc|}
\hline \multicolumn{3}{|c|}{ DBU } & \multicolumn{3}{c|}{ DBU } \\
\hline Time & Average & Std Error & Time & Average & Std Error \\
\hline 0 & 2.256005 & 1.31608 & 0 & 1.666507 & 0.695752 \\
5 & 3.600584 & 1.353348 & 5 & 5.578874 & 2.159499 \\
15 & 6.954194 & 1.824225 & 15 & 5.472081 & 0.775909 \\
30 & 11.14033 & 2.124108 & 30 & 8.8353 & 0.914478 \\
60 & 18.32306 & 2.04997 & 60 & 14.69157 & 1.168863 \\
180 & 33.90574 & 1.548675 & 180 & 31.48601 & 1.52326 \\
300 & 40.5003 & 1.340304 & 300 & 42.29793 & 1.423256 \\
\hline
\end{tabular}

\begin{tabular}{|rcc|rcc|}
\hline \multicolumn{3}{|c|}{ Piperidine } & \multicolumn{3}{c|}{ Piperidine } \\
\hline Time & Average & Std Error & Time & Average & Std Error \\
\hline 0 & 1.976981 & 0.709695 & 0 & 1.180353 & 0.418479 \\
5 & 3.896321 & 1.001627 & 5 & 1.444102 & 0.382956 \\
15 & 7.474367 & 1.236934 & 15 & 1.676309 & 0.448716 \\
30 & 12.10695 & 1.51784 & 30 & 1.825646 & 0.463475 \\
60 & 19.91812 & 1.515218 & 60 & 2.523084 & 0.417597 \\
180 & 36.00322 & 1.329532 & 180 & 4.26883 & 0.478682 \\
300 & 41.69356 & 1.702057 & 300 & 5.882649 & 0.538434 \\
\hline
\end{tabular}

\begin{tabular}{|rcc|rcc|}
\hline \multicolumn{3}{|c|}{ NMM } & \multicolumn{3}{c|}{ NMM } \\
\hline Time & Average & Std Error & Time & Average & Std Error \\
\hline 0 & 0.385769 & 0.35783 & 0 & 0.736064 & 0.245138 \\
5 & 0.260452 & 0.236574 & 5 & 0.703178 & 0.271918 \\
15 & 0.489344 & 0.449632 & 15 & 0.730255 & 0.331685 \\
30 & 0.027937 & 0.027937 & 30 & 0.871632 & 0.484795 \\
60 & 0.043181 & 0.043181 & 60 & 0.795134 & 0.334548 \\
180 & 0.495682 & 0.148932 & 180 & 0.653601 & 0.320775 \\
300 & 0.233853 & 0.043659 & 300 & 0.650147 & 0.243972 \\
\hline
\end{tabular}

\begin{tabular}{|rcc|rcc|}
\hline \multicolumn{3}{|c|}{ DIEA } & \multicolumn{3}{c|}{ DIEA } \\
\hline Time & Average & Std Error & Time & Average & Std Error \\
\hline 0 & 0.150717 & 0.407326 & 0 & 1.306948 & 0.009526 \\
5 & 0 & 0.333333 & 5 & 1.268584 & 0.145731 \\
15 & 0.164933 & 0.332509 & 15 & 1.248164 & 0.140538 \\
30 & 0.163997 & 0.332514 & 30 & 1.259028 & 0.136698 \\
60 & 0.117301 & 0.332748 & 60 & 1.217432 & 0.121722 \\
180 & 0.373977 & 0.331466 & 180 & 1.198897 & 0.057022 \\
300 & 0.059465 & 0.333036 & 300 & 0.978214 & 0.09215 \\
\hline
\end{tabular}




\section{SPPS Procedures:}

Peptides were synthesized in the following manner: Fmoc-Gly-Chlorotrityl resin was swelled in DMF for 10 minutes in a ChemGlass Peptide Synthesis Vessel using nitrogen as an agitator. Solvents were removed from the vessel using vacuum.

Fmoc-deprotection steps were carried out using $20 \%$ piperidine in DMF for 2 minutes followed by a treatment of fresh reagent solution for 8 minutes. The resin was then washed $5 x$ for 1 min each with dry DMF.

Coupling steps were carried out by pre-activating 5.0 eq of Fmoc-Xaa-OH with 4.9 eq HATU and 10.0 eq of NMM (relative to moles of peptide on-resin) in DMF at an approximate concentration of $0.2 \mathrm{M}$ concentration. Each coupling step was agitated with nitrogen gas for $30 \mathrm{~min}$. Once complete, the resin was washed $3 x$ for 1 min each with dry DMF.

Addition of the thioamide was achieved by dissolving 2 eq of the thioacylating agent (Fmoc-Xaa(S)-Nbt) in dry DCM with DIEA (2 eq) at an approximate concentration of $0.1 \mathrm{M}$. This solution was agitated with the resin using nitrogen gas for $30 \mathrm{~min}$. This procedure was repeated a second time. Following completion of the coupling steps, the resin was washed with dry DCM $3 x$ for $1 \mathrm{~min}$.

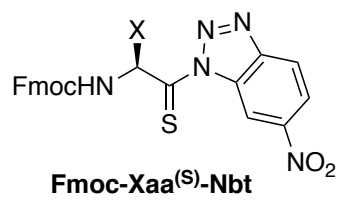

Thioamide protection was achieved with $0.4 \mathrm{M}$ methyl-iodide and $0.05 \mathrm{M}$ DIEA in dry DMF. The resin was agitated for $6 \mathrm{~h}$ on rotary mixer and drained of solvent. Fresh reagent of $0.4 \mathrm{M}$ methyl-iodide and $0.05 \mathrm{M}$ DIEA in dry DMF was added and the resin was agitated for an additional $6 \mathrm{~h}$ on a rotary mixer. The reaction can be monitored by cleaving a small amount of resin with $20 \%$ HFIP/DCM and checked via UPLC.

Figure S2. Partial thiomidate protection visualized with UPLC.

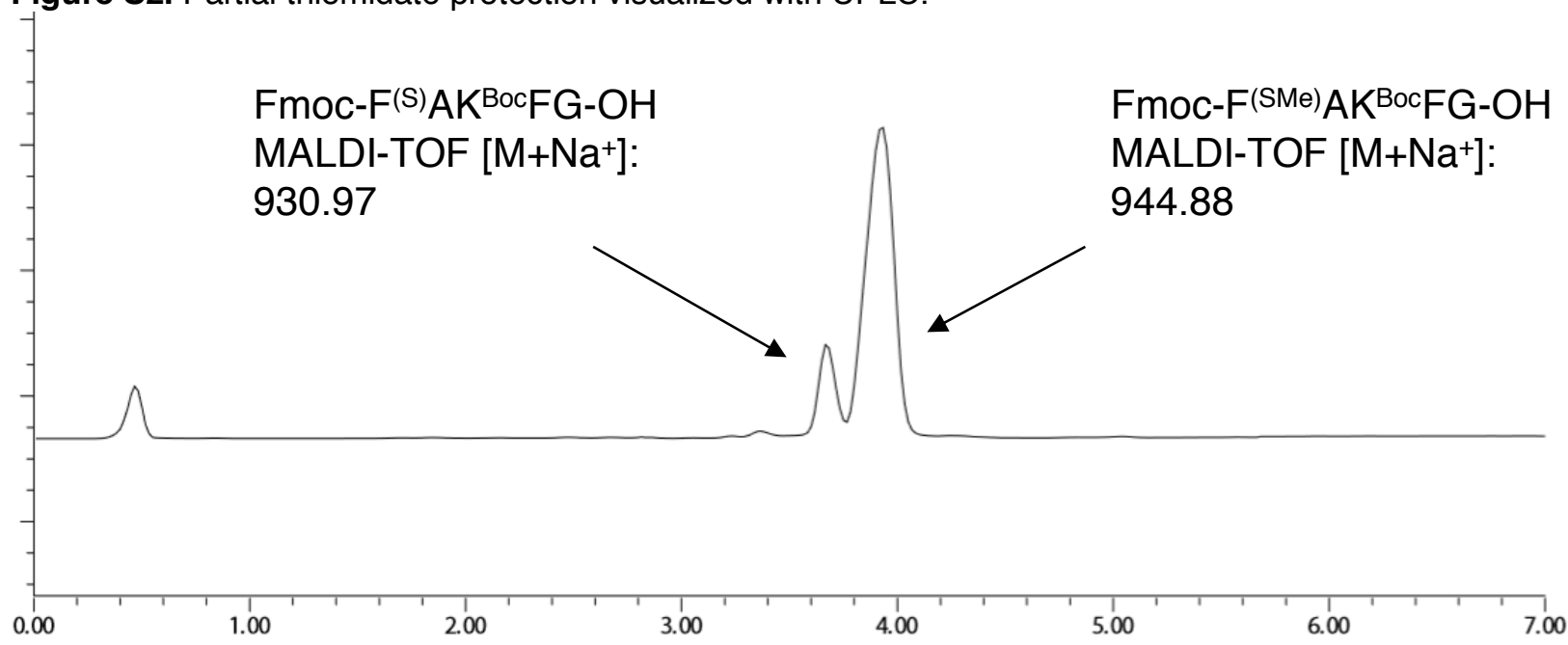

Thioloysis to regenerate the thioamide was achieved by suspending the resin in a peptide synthesis vessel with $2 \mathrm{~mL}$ of $0.05 \mathrm{M}$ collidine in dry DMF. Hydrogen sulfide gas is bubbled through the vessel 15 seconds and the system was sealed $1 \mathrm{~h}$. Upon completion, the resin is checked for full conversion by cleaving a small amount of resin with $20 \%$ HFIP/DCM.

Peptide cleavage Upon full conversion, 30:70 TFA/DCM is used to cleave the peptide for 15 minutes. Post TFA cleavage, peptide solution is transferred to a Falcon Tube and dried with a gentle air flow to a glassy film. Cold diethyl ether is added forming a small white precipate and the peptide is then centrifuged 
at $10,000 \mathrm{rpm}$ for 10 minutes. Waste diethyl ether is collected, and fresh cold diethyl ether is added and centrifuged again. Diethyl ether waste is again collected, and the small precipitated peptide was analyzed via HPLC.

\section{HPLC Traces of Peptides:}

Epimerization found in a similar manner as UPLC dimer studies

All traces were montiored for absorbance at $254 \mathrm{~nm}$

Table S3

\begin{tabular}{|c|c|c|c|c|}
\hline $\begin{array}{c}\text { Peptide } \\
\text { Number }\end{array}$ & Sequence & $\begin{array}{c}\text { Thioimidate } \\
\text { protection }\end{array}$ & \% Epimerization & Gradient \\
\hline $\mathbf{8}$ & $\mathrm{H}-\mathrm{KAF}^{\mathrm{S}} \mathrm{AKFG}-\mathrm{OH}$ & No & 12.8 & 1 \\
\hline $\mathbf{9}$ & $\mathrm{H}-\mathrm{KAF}^{\mathrm{S}} \mathrm{AKFG}-\mathrm{OH}$ & Yes & None Observed & 1 \\
\hline $\mathbf{R P 1}$ & $\mathrm{H}-\mathrm{KAf}^{\mathrm{S}} \mathrm{AKFG}-\mathrm{OH}$ & No & 8.3 & 1 \\
\hline $\mathbf{1 0}$ & $\mathrm{H}-\mathrm{AAKAF}$ AKFG-OH & No & 22.1 & 1 \\
\hline $\mathbf{1 1}$ & $\mathrm{H}-\mathrm{AAKAF}$ AKFG-OH & Yes & None Observed & 1 \\
\hline $\mathbf{R P 2}$ & $\mathrm{H}-\mathrm{AAKAf} \mathrm{AKFG}-\mathrm{OH}$ & No & 12.9 & 1 \\
\hline
\end{tabular}




\section{Gradient Conditions:}

\begin{tabular}{|crr|}
\hline \multicolumn{3}{|c|}{1} \\
\hline Time & \% Water & \% Acetonitrile \\
\hline 0.00 & 95 & 5 \\
5.00 & 95 & 5 \\
5.01 & 80 & 20 \\
18.00 & 70 & 30 \\
24.00 & 5 & 95 \\
25.00 & 5 & 95 \\
25.01 & 95 & 5 \\
26.00 & 95 & 5 \\
\hline
\end{tabular}

Flow rates were held constant at $1.00 \mathrm{~mL} / \mathrm{min}$

\section{H-KAFSAKFG-OH 1-3}

Calc'd $\left[\mathrm{M}+\mathrm{H}^{+}\right]$: 785.00

Unprotected during SPPS:

Mass via MALDI-TOF: 785.87

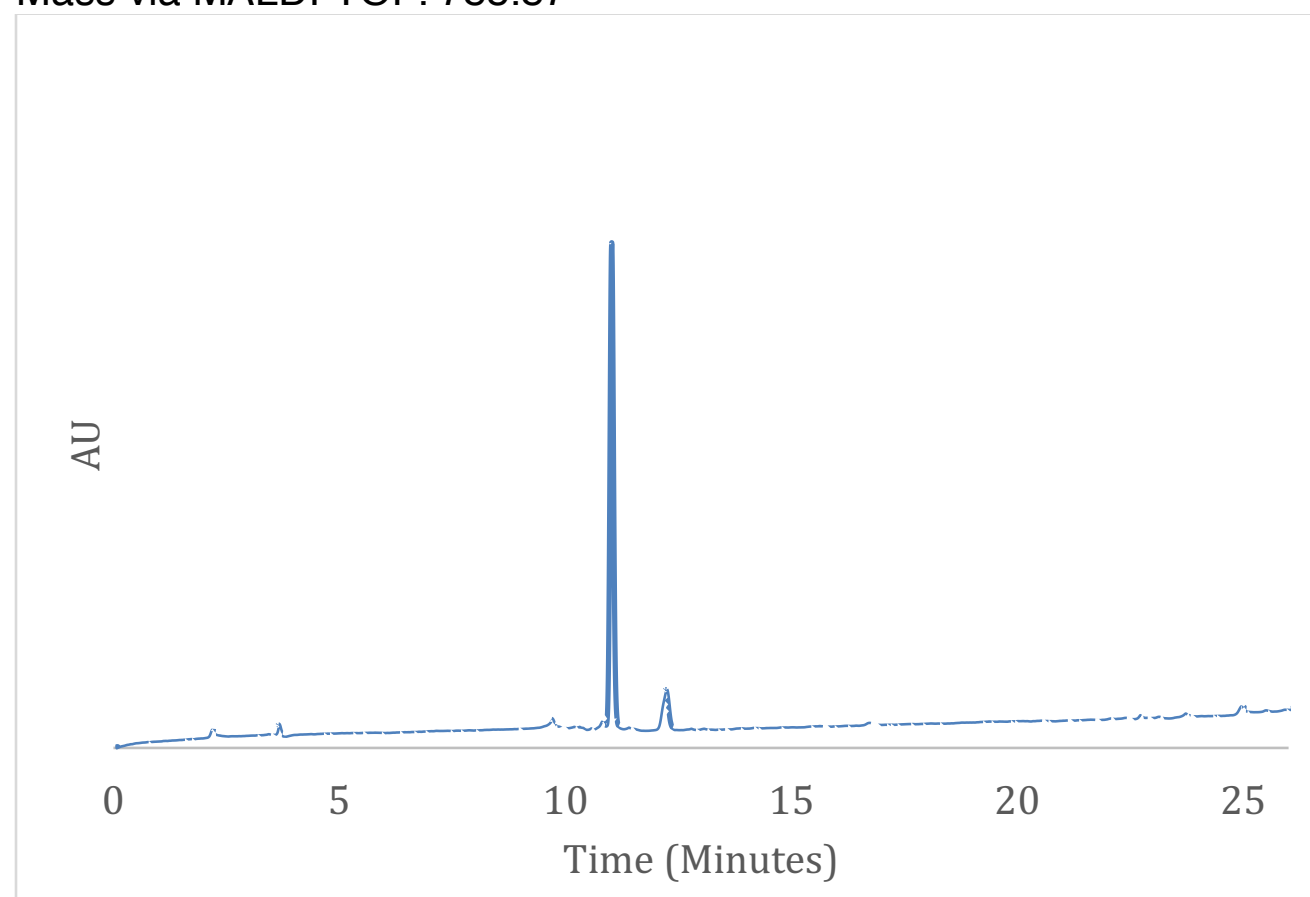




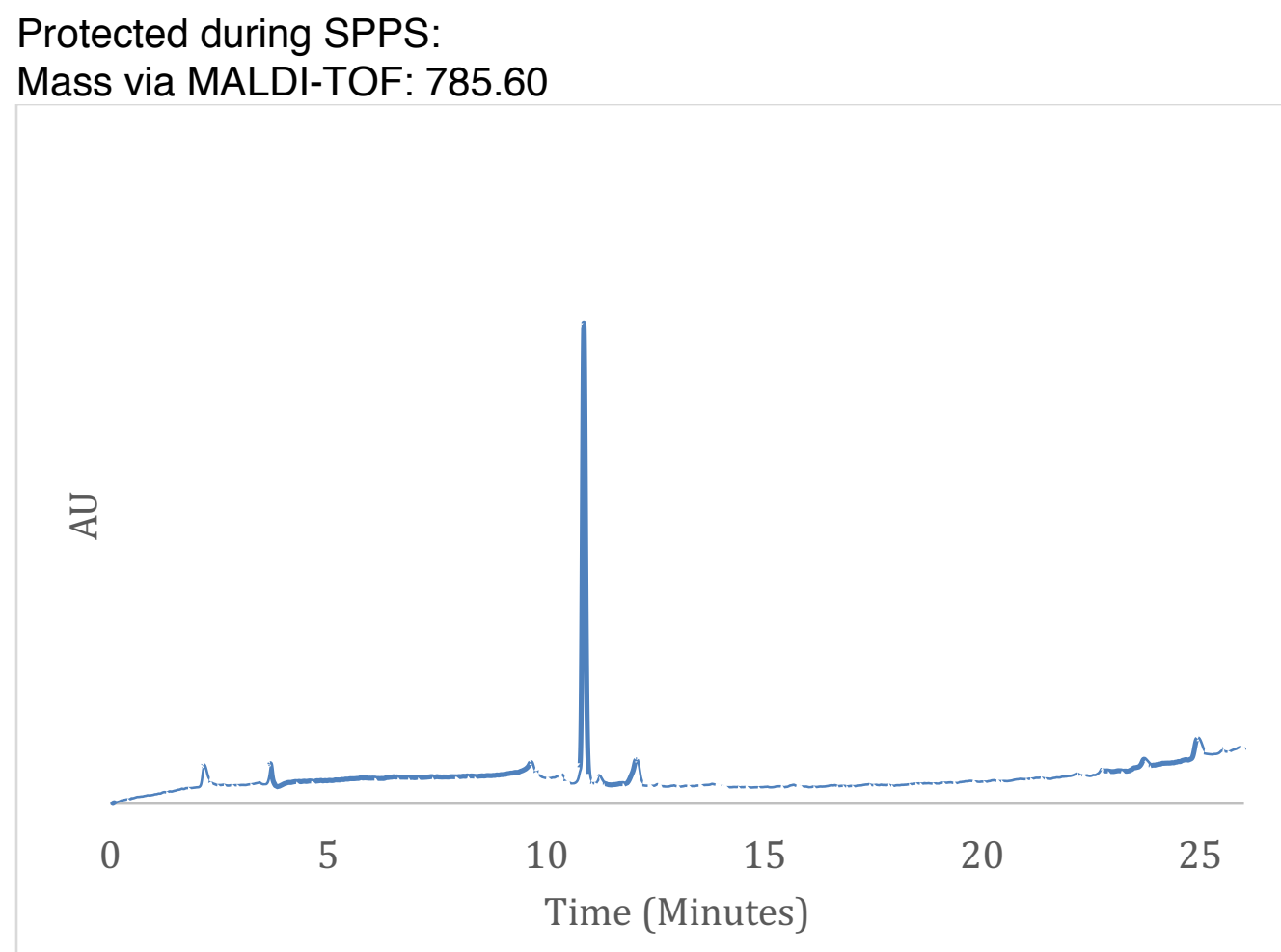

D-isomer for reference:

Mass via MALDI-TOF: 785.71

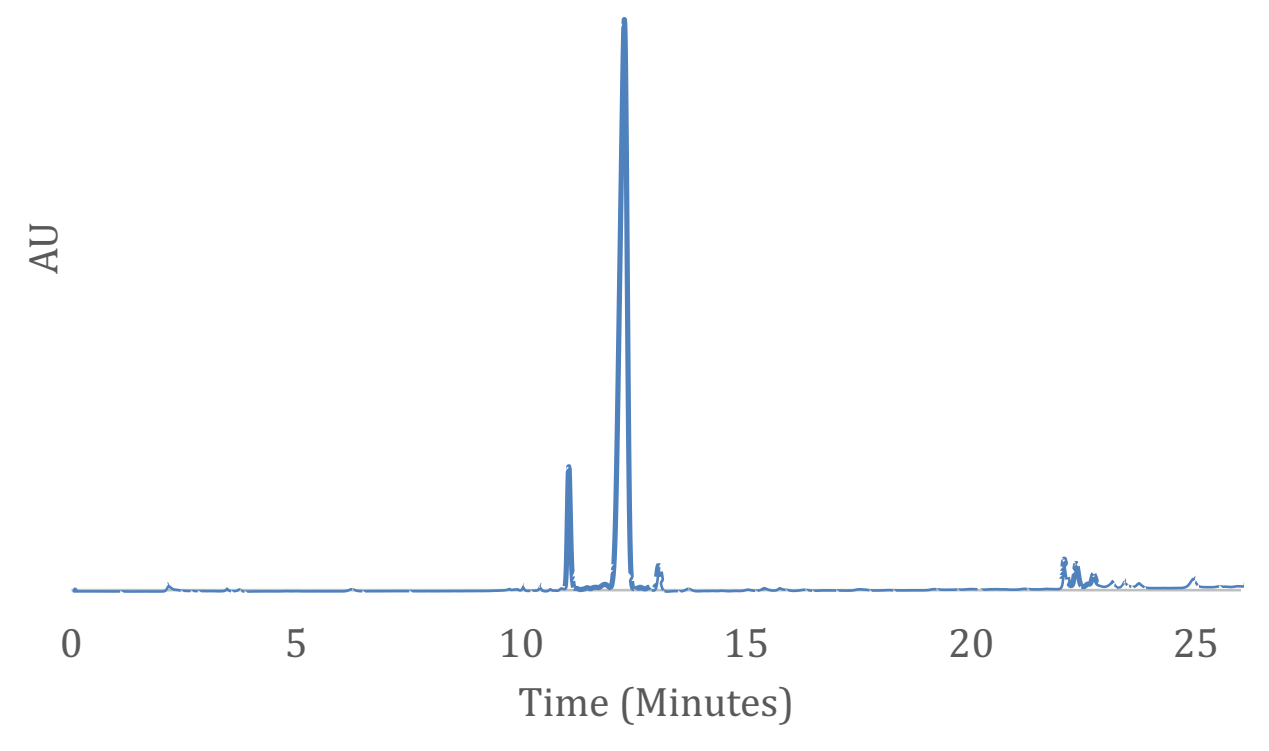


H-AAKAF'AKFG-OH 4-5

Calc'd $\left[\mathrm{M}+\mathrm{H}^{+}\right]$: 927.16

Unprotected during SPPS:

Mass via MALDI-TOF: 927.98

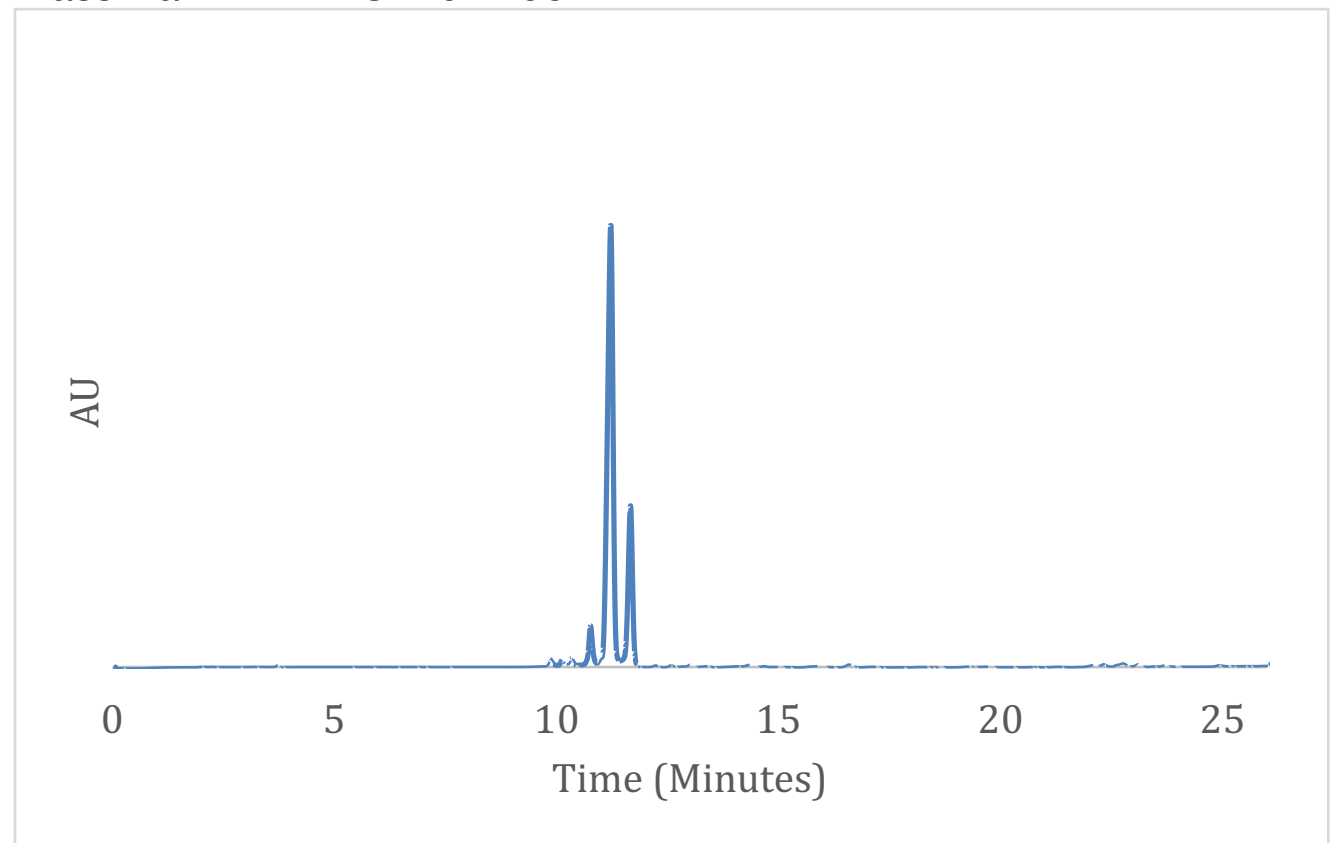

Protected during SPPS:

Mass via MALDI-TOF: 927.83

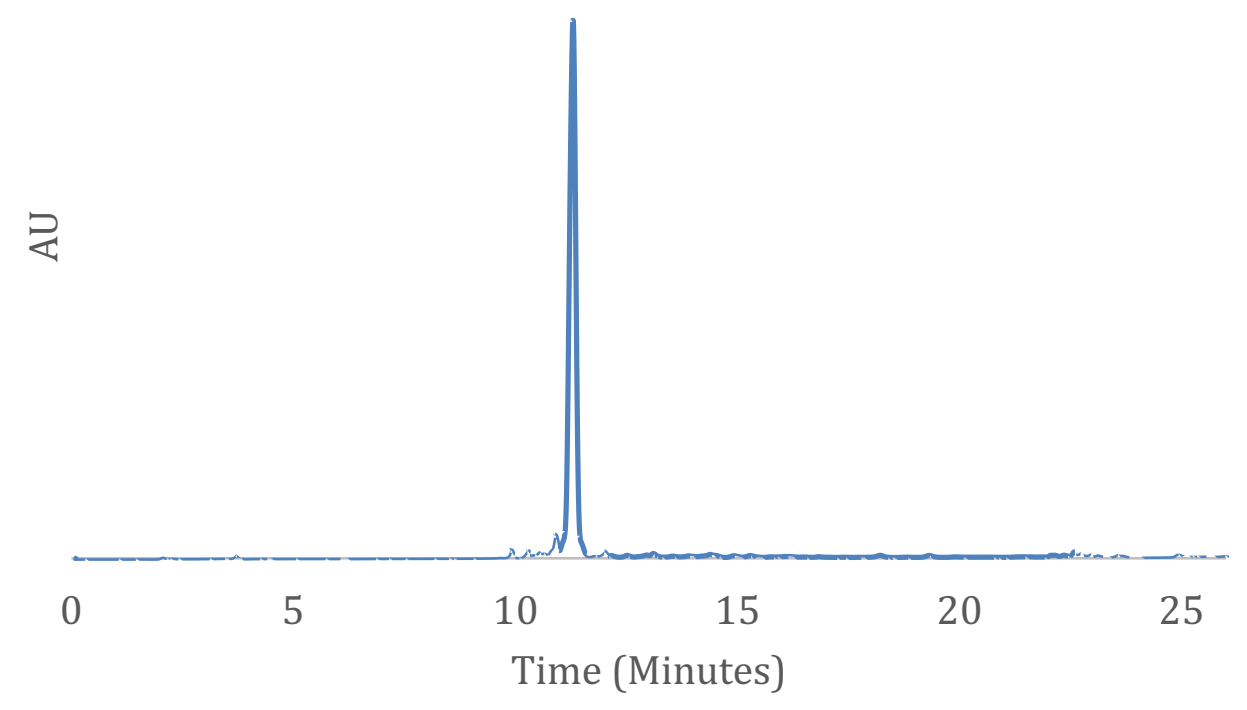


D-isomer for reference:

Mass via MALDI-TOF: 927.95

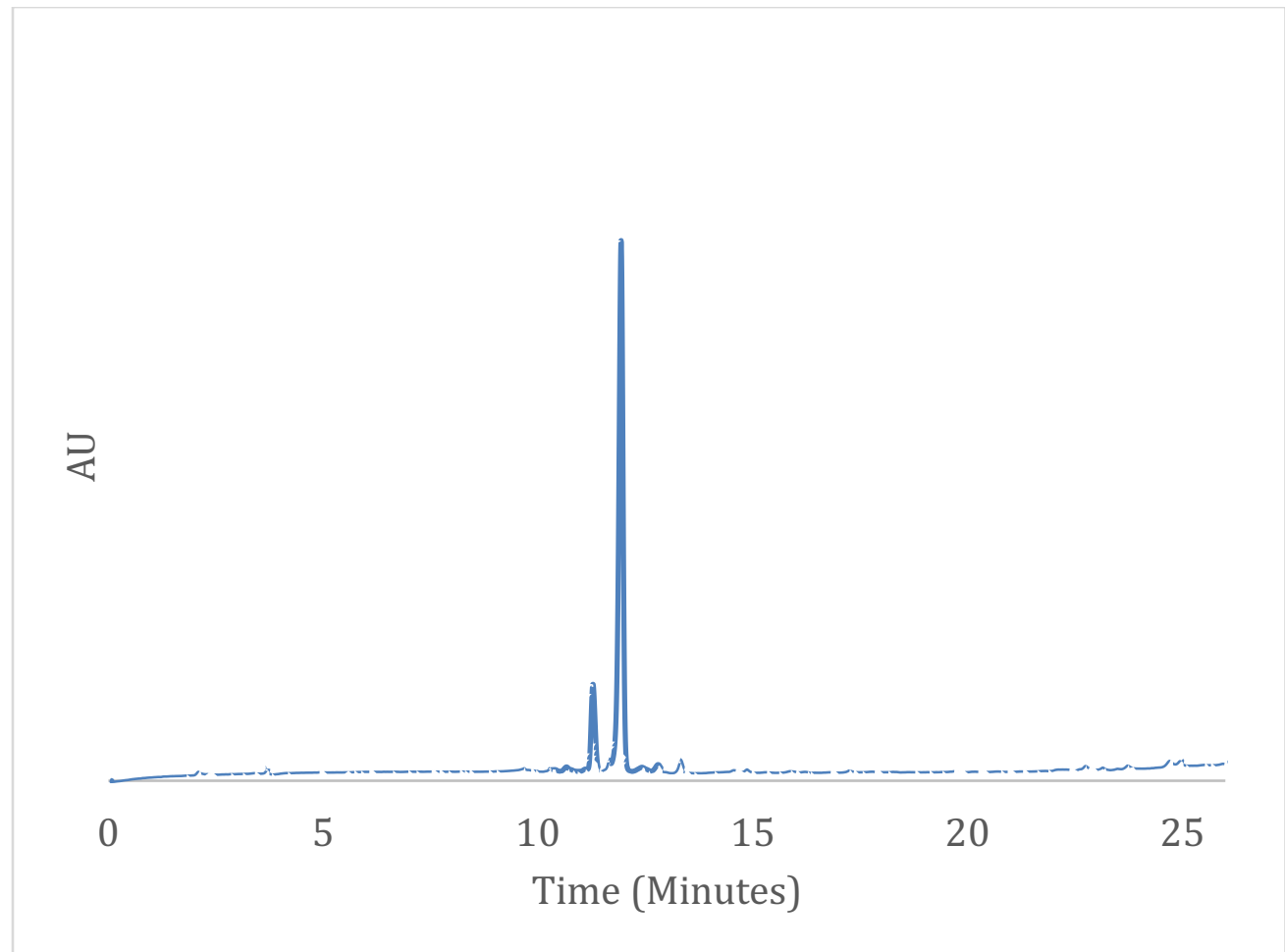




\section{NMR SPECTRA}

Fig S3. ${ }^{1 \mathrm{H}} \mathrm{NMR}$ of Z-Phe-Ala-OMe $\left(400 \mathrm{MHz}, \mathrm{CDCl}_{3}\right)$

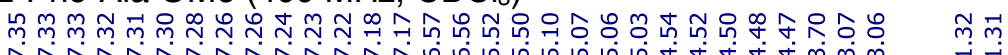<smiles>COC(=O)[C@H](C)NC(=O)[C@H](Cc1ccccc1)NC(=O)OCc1ccccc1</smiles>

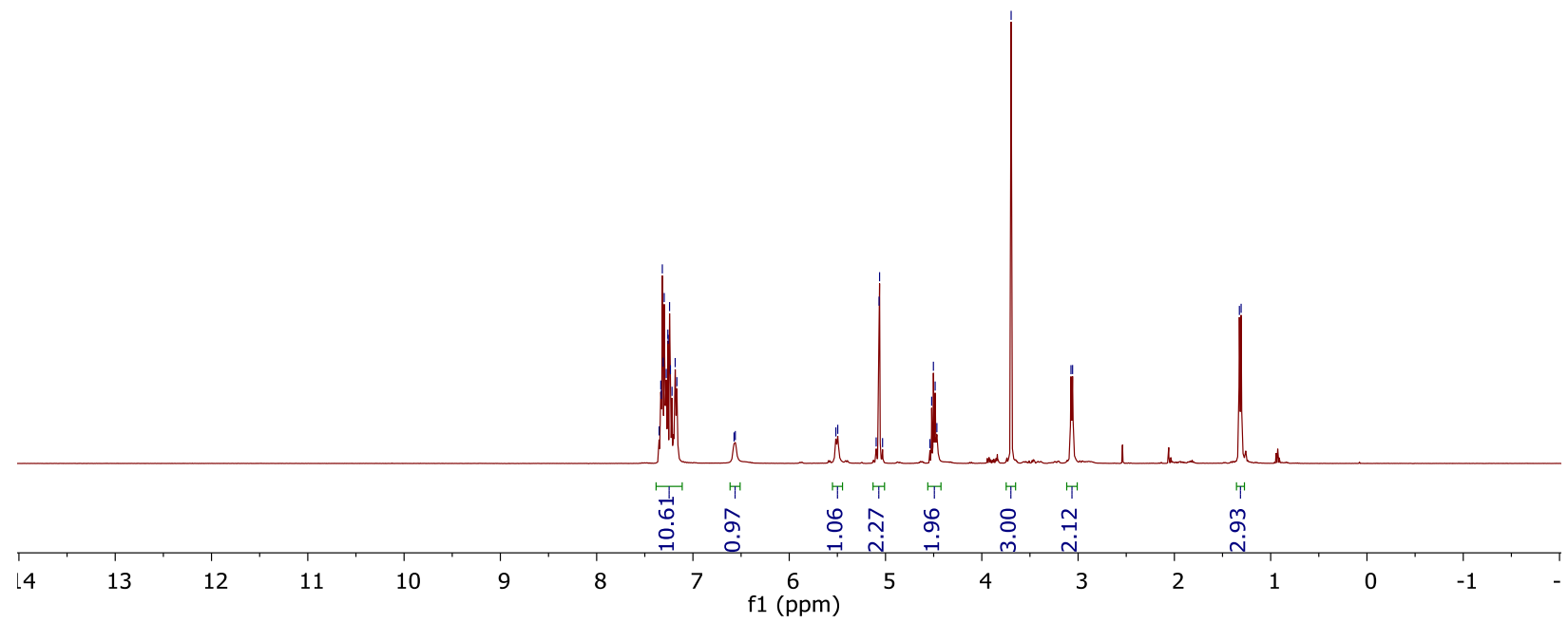


Fig S4 ${ }^{1} \mathrm{H}$ and $13 \mathrm{C}$ of Z-Phes-Ala-OMe (400 MHz, Acetone-d6)

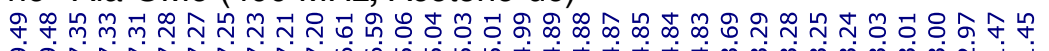

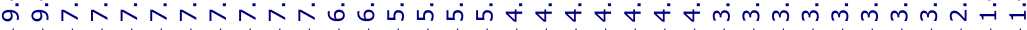

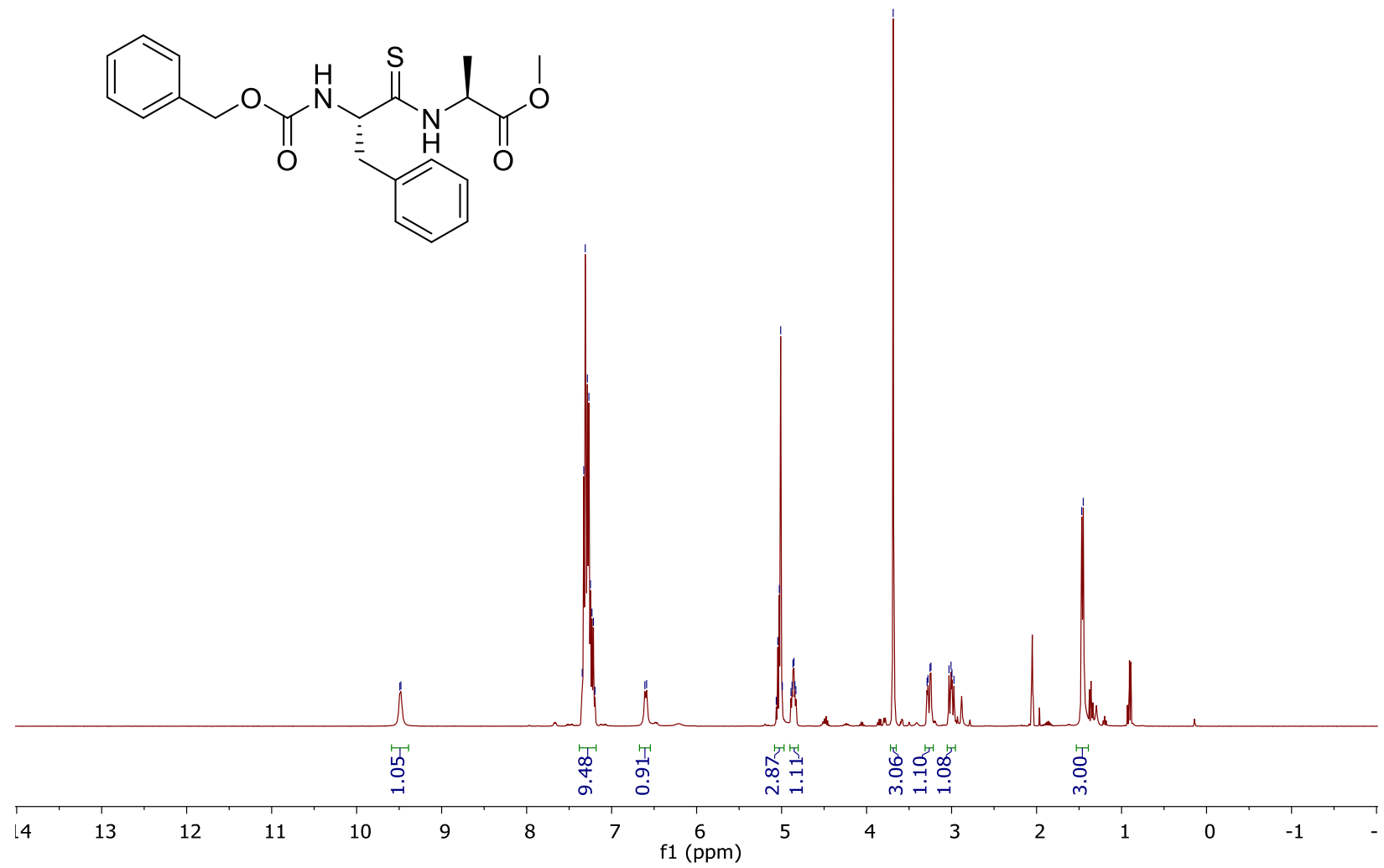


Fig S5 ${ }^{13} \mathrm{C}-\mathrm{NMR}$ of Z-Phes-Ala-OMe (100 MHz, Acetone-d6)

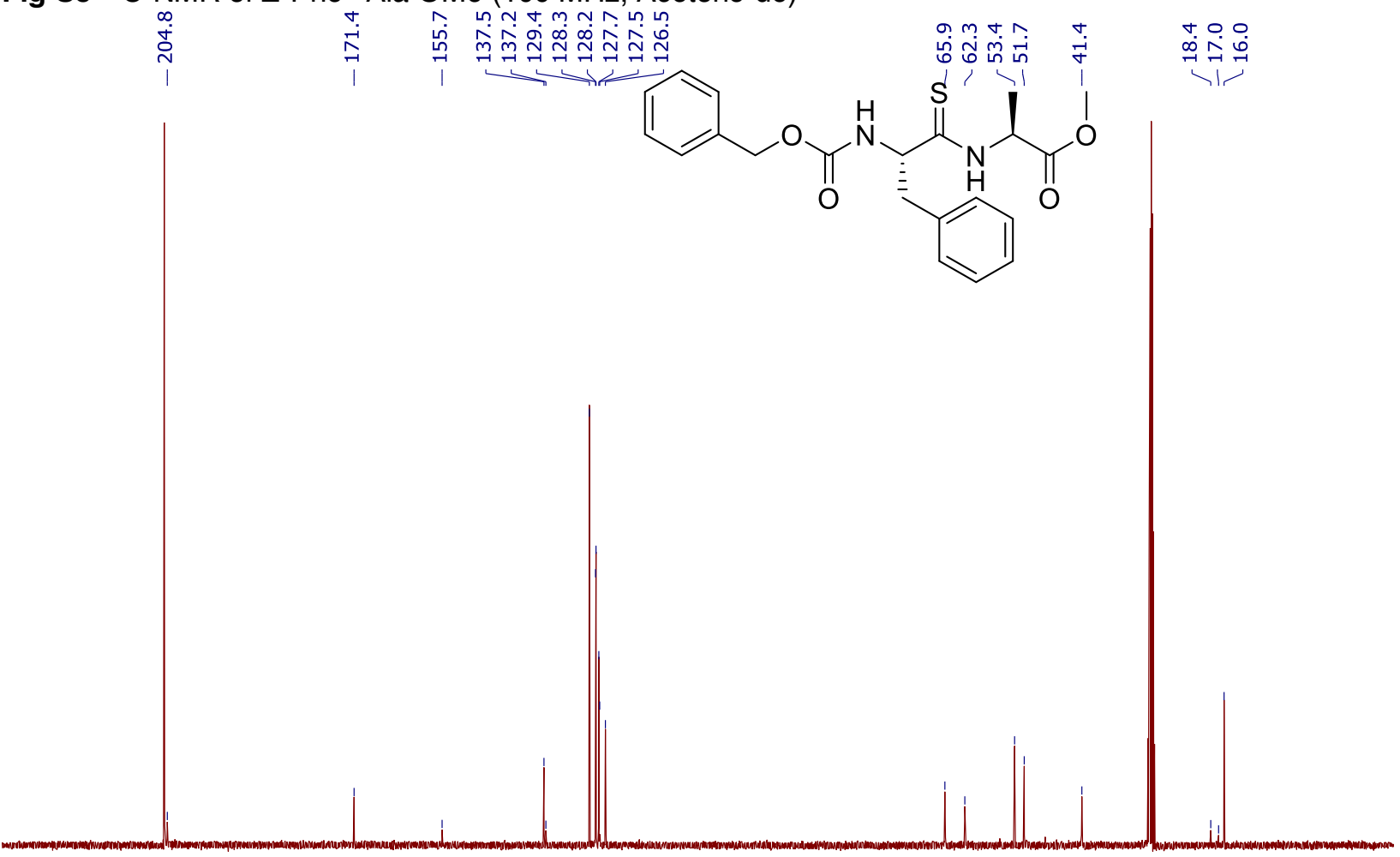

$\begin{array}{llllllllllllllllllllllllllllllllllll}230 & 220 & 210 & 200 & 190 & 180 & 170 & 160 & 150 & 140 & 130 & 120 & 110 & 100 & 90 & 80 & 70 & 60 & 50 & 40 & 30 & 20 & 10 & 0 & -10\end{array}$ 
Fig 56 'H NMR Z-PhesMe-Ala-OMe $(400 \mathrm{MHz}$, Acetone-d6)

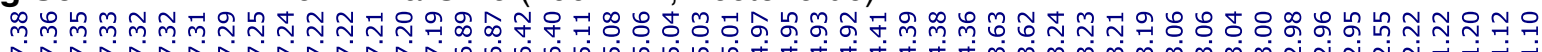

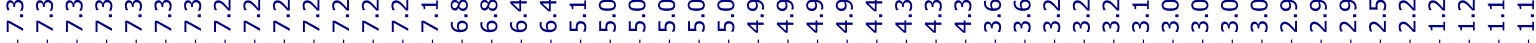

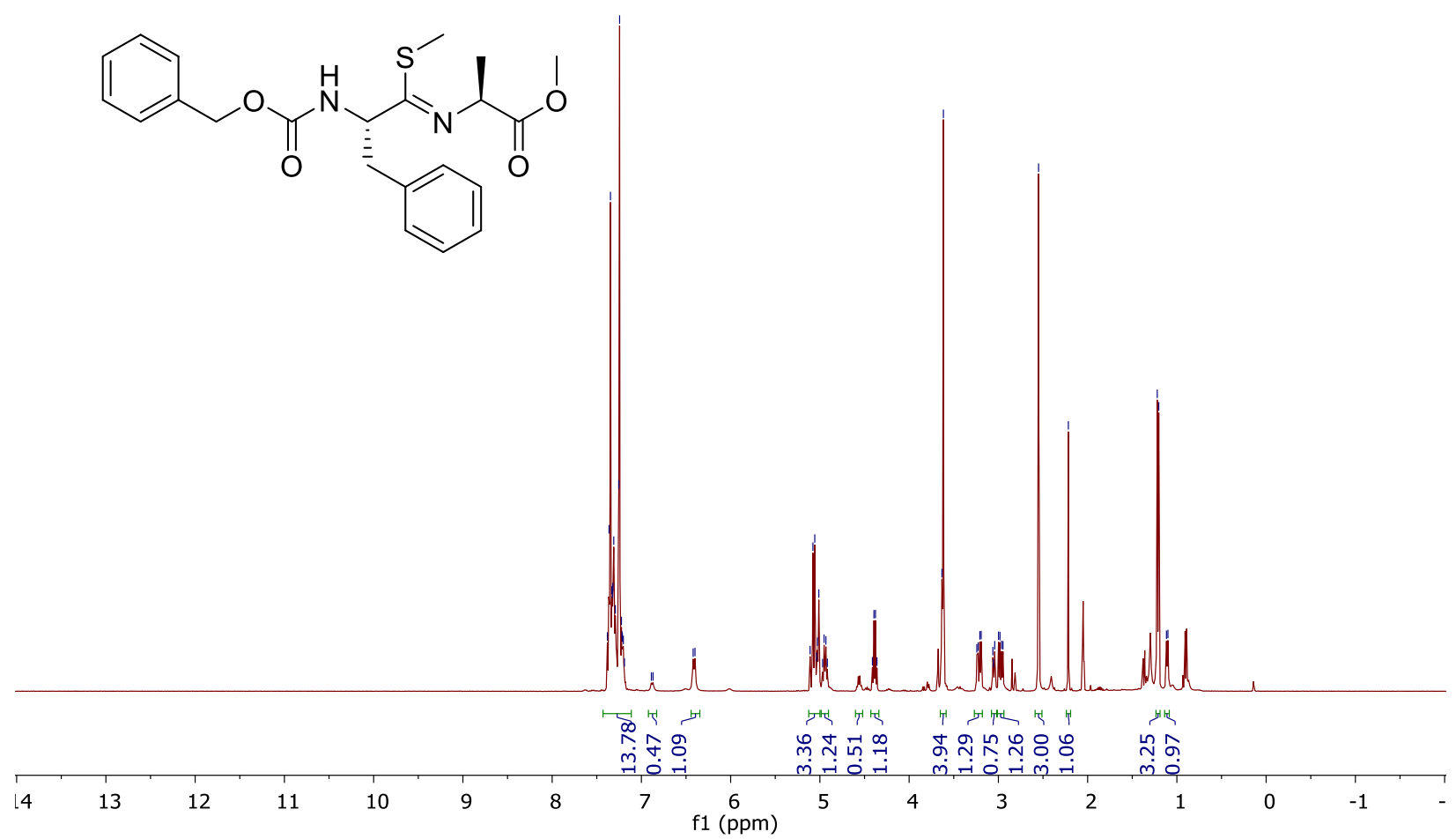


Fig S7 ${ }^{13} \mathrm{C}$ NMR Z-PheSMe-Ala-OMe (100 MHz, Acetone-d6)

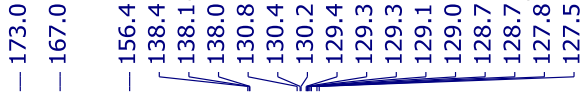

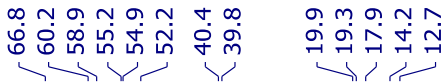

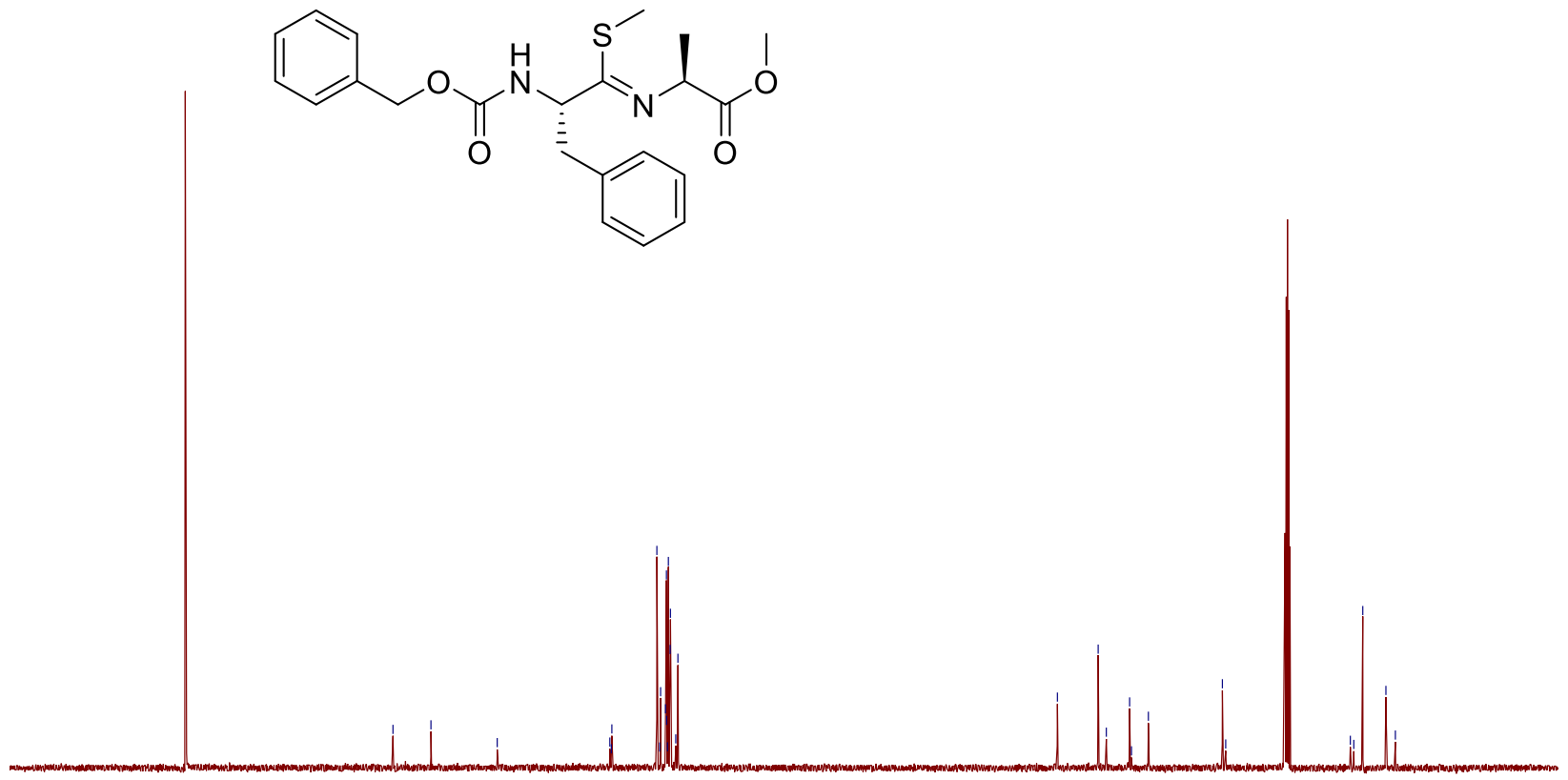

$\begin{array}{lllllllllllllllllllllllll}230 & 220 & 210 & 200 & 190 & 180 & 170 & 160 & 150 & 140 & 130 & 120 & \begin{array}{c}110 \\ 100\end{array} & 100 & 90 & 80 & 70 & 60 & 50 & 40 & 30 & 20 & 10 & 0 & -10\end{array}$ 


\section{ANALYTICAL UPLC TRACES}

Fig S8 Analytical UPLC-MS(ESI) analysis of Z-Phe-Ala-OMe.

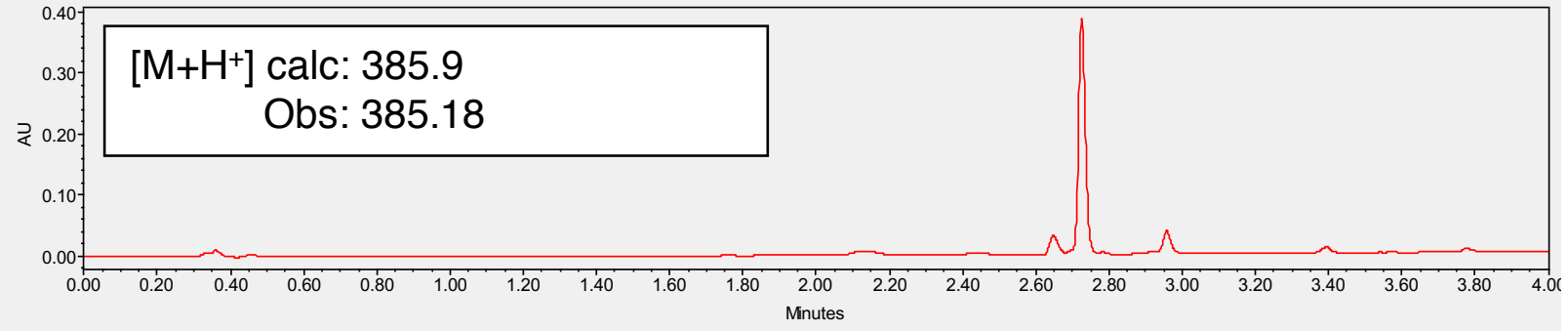

Fig S9 Analytical UPLC-MS(ESI) analysis of Z-Phes-Ala-OMe.

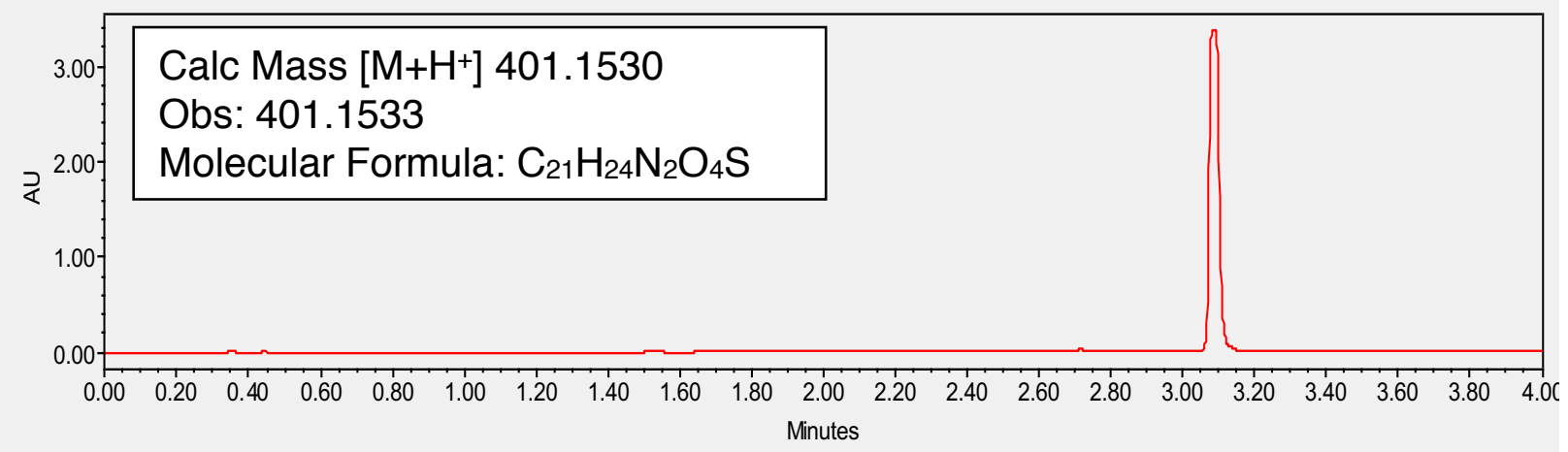

Fig S10 Analytical UPLC-MS(ESI) analysis of Z-PheSMe-Ala-OMe.

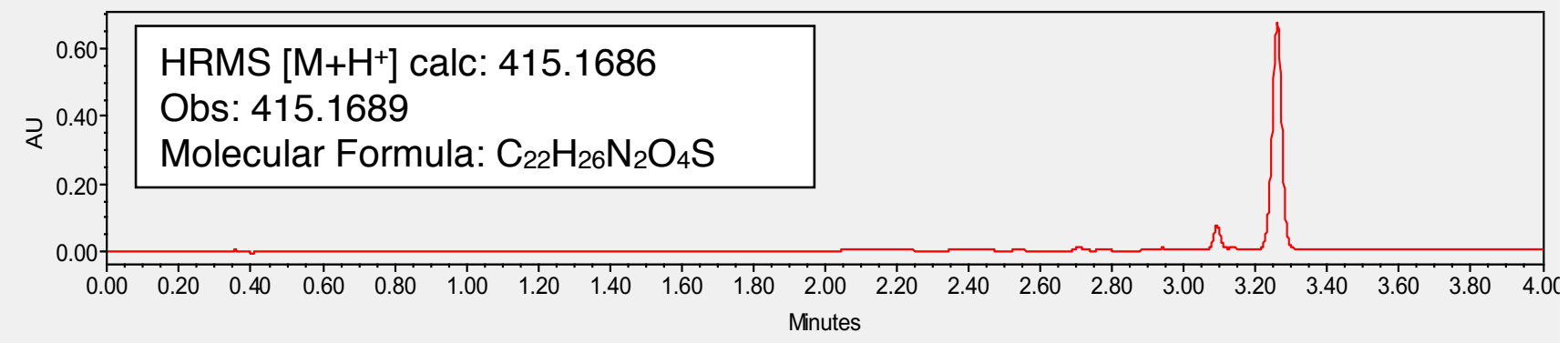




\section{Computational Details}

All computations were carried out using the Gaussian 09 software package ${ }^{4}$. Geometries were calculated using Density Functional Theory with the exploratory B3LYP functional5 basis set. All geometries were verified to be local minimums by the absence of imaginary frequencies in the hessian calculation. Orbital energies were calculated using NBO 3.16 as implemented in Gaussian 09.

\begin{tabular}{lrrr} 
Formamide, X & \multicolumn{2}{c}{} \\
Symbol & \multicolumn{2}{c}{$\mathrm{Y}$} \\
$\mathrm{C}$ & -0.865039 & -0.645974 & -0.000015 \\
$\mathrm{O}$ & -1.951184 & -0.097597 & 0.000027 \\
$\mathrm{H}$ & -0.760123 & -1.746458 & -0.000047 \\
$\mathrm{~N}$ & 0.344648 & -0.018881 & -0.000066 \\
$\mathrm{C}$ & 1.589803 & -0.764175 & 0.000026 \\
$\mathrm{H}$ & 1.377223 & -1.834448 & 0.000098 \\
$\mathrm{H}$ & 2.18704 & -0.529723 & -0.888121 \\
$\mathrm{H}$ & 2.186963 & -0.529608 & 0.888191 \\
$\mathrm{C}$ & 0.42311 & 1.433512 & 0.000004 \\
$\mathrm{H}$ & 0.953912 & 1.790078 & 0.889199 \\
$\mathrm{H}$ & 0.954014 & 1.790071 & -0.889133 \\
$\mathrm{H}$ & -0.589338 & 1.832854 & -0.00003
\end{tabular}

Energy $\quad-248.59016305$

\section{Formthioamide, $x$}

\begin{tabular}{lrrr} 
Symbol & \multicolumn{2}{c}{$\mathrm{Y}$} & \\
$\mathrm{C}$ & -0.385839 & -0.671102 & 0.000676 \\
$\mathrm{H}$ & -0.259017 & -1.754563 & 0.001087 \\
$\mathrm{~N}$ & 0.794404 & -0.028081 & 0.001338 \\
$\mathrm{C}$ & 2.054519 & -0.759774 & -0.000717 \\
$\mathrm{H}$ & 1.859701 & -1.831881 & 0.000648 \\
$\mathrm{H}$ & 2.64163 & -0.508472 & -0.890177 \\
$\mathrm{H}$ & 2.645284 & -0.50684 & 0.885803 \\
$\mathrm{C}$ & 0.899355 & 1.424842 & 0.000034 \\
$\mathrm{H}$ & -0.102115 & 1.849665 & 0.008747 \\
$\mathrm{H}$ & 1.449289 & 1.760904 & 0.884722 \\
$\mathrm{H}$ & 1.433126 & 1.76121 & -0.894516 \\
$\mathrm{~S}$ & -1.914809 & -0.033578 & -0.000352
\end{tabular}

Energy (hartrees) $\quad 571.54694277$ 


\begin{tabular}{lrrr}
\multicolumn{4}{c}{ Methyl (Z)-N-methylethaneimidothioate, X } \\
Symbol X & \multicolumn{3}{c}{ Z } \\
C & -0.424876 & 0.190955 & 0.000014 \\
H & -0.345209 & 1.289359 & 0.000067 \\
N & -1.516515 & -0.438502 & -0.000021 \\
C & -2.751509 & 0.323819 & -0.000004 \\
H & -2.596295 & 1.413567 & 0.000017 \\
H & -3.342376 & 0.051376 & -0.879452 \\
H & -3.342337 & 0.051364 & 0.879469 \\
S & 1.130649 & -0.65939 & 0.000008 \\
C & 2.272548 & 0.769764 & -0.000011 \\
H & 2.148123 & 1.37851 & 0.895924 \\
H & 3.278387 & 0.349747 & -0.00014 \\
H & 2.147948 & 1.378601 & -0.895859 \\
& & & \\
& & & -571.53055987
\end{tabular}

Table X. $\pi$ and $\pi^{*}$ Orbital Energies Calculated by NBO Analysis

$\begin{array}{rrrr} & \text { oxo, } \mathbf{x}(\mathbf{C}=\mathbf{0}) & \text { thio, } \mathbf{x}(\mathbf{C}=\mathbf{S}) & \text { imidothiolate, } \mathbf{x}(\mathbf{C}=\mathbf{N}) \\ \pi^{*} & 0.01096 & -0.06332 & 0.01004 \\ \pi & -0.3679 & -0.28745 & -0.33847\end{array}$




\section{REFERENCES}

(1) Shalaby, M. A.; Grote, C. W.; Rapoport, H. Thiopeptide Synthesis. r-Amino Thionoacid Derivatives of Nitrobenzotriazole as Thioacylating Agents. J. Org. Chem. 1996, 61, 9045-9048. https://doi.org/10.1021/jo961245q.

(2) Landeros, J. M.; Juaristi, E. Mechanochemical Synthesis of Dipeptides Using MgAl Hydrotalcite as Activating Agent under Solvent-Free Reaction Conditions. European J. Org. Chem. 2017, 2017 (3), 687-694. https://doi.org/10.1002/ejoc.201601276.

(3) Szantai-Kis, M. M.; Walters, C. R.; Barrett, T. M.; Hoang, E. M.; Petersson, J. J. Thieme Chemistry Journals Awardees - Where Are They Now? Improved Fmoc Deprotection Methods for the Synthesis of Thioamide-Containing Peptides and Proteins. Synlett 2017, 1789-1794. https://doi.org/10.1055/s-0036-1589027.

(4) M. J. Frisch, G. W. Trucks, H. B. Schlegel, G. E. Scuseria, M. A. Robb, J. R. Cheeseman, G. Scalmani, V. Barone, G. A. Petersson, H. Nakatsuji, X. Li, M. Caricato, A. Marenich, J. Bloino, B. G. Janesko, R. Gomperts, B. Mennucci, H. P. Hratchian, J. V. Ort, W. C. Gaussian 09, Revision A.02. 2016.

(5) Becke, A. D. Electronic Population Analysis on LCAO-MO Molecular Wave Functions. I. J. Chem. Phys. 1993, 98, 4439. https://doi.org/10.1063/1.464913.

(6) E. D. Glendening, A. E. Reed, J. E. Carpenter, and F. W. NBO Version 3.1. 